\title{
EDITORIAL
}

\section{Finally time for rapid response systems to be well MET in Europe?}

\author{
Markus B Skrifvars ${ }^{1 *}$ and Ignacio Martin-Loeches ${ }^{2}$
}

Time is life. In medicine there are many "time-dependent" diseases: sepsis and cardiac arrest to name but two $[1,2]$. In order to improve patient outcome, it is imperative to define and characterize hospital workflows to facilitate good process of care. Several factors need to be synchronized, including coordination between different departments in the hospital [3]. Early communication and a multidisciplinary approach can dramatically change the management of patients. The goal of modern intensive care medicine is to optimize and maximize quality of patient care. It is desirable to foster an overview of the process of critical care and base it on clinical need of patients and less on hospital location. Clinical management and monitoring of severely ill patients before admission to intensive care units (ICU) have frequently been shown to be suboptimal $[4,5]$. Delays in patient admission to ICU are associated with a longer hospital stay and worse outcome. Recently, Harris et al. prospectively analysed the outcome of a large UK population from 48 hospitals and concluded that the deteriorating ward patient has a high short-term mortality; however, with early ICU admission an impressive $50 \%$ reduction of 90-day mortality is possible [6].

Clinical conditions at risk are usually preceded by pathophysiological alterations that are both detectable and preventable. As early as the late 1990s, patient-atrisk teams, medical emergency teams (METs) or rapid response teams (RRT) were created to early detect patients at risk on general wards [7]. In the USA, the Institute for Healthcare Improvement (IHI) recommended, more than 10 years ago, that hospitals should implement RRTs and/or METs for the identification of non-ICU patients at risk of deterioration $[8,9]$.

\footnotetext{
*Correspondence: markus.skrifvars@hus.fi

${ }^{1}$ Division of Critical Care, Department of Anaesthesiology, Intensive Care and Pain Medicine, Helsinki University and Helsinki University Hospital, Helsinki, Finland

Full author information is available at the end of the article
}

Meta-analyses, including 30 before-after studies, cohort studies and cluster randomized trials found that implementation of an RRT/MET is associated with a reduction in non-ICU cardiopulmonary arrests but the effect on hospital mortality is less clear $[10,11]$. In the UK, early warning scores (EWS) based on "track and trigger" systems have for several years been used to flag and alert patients at risk and develop a rapid response by in-hospital teams with critical care skills to stabilize patients and expedite admission to ICU [12].

Thus far the evidence on MET/RRT adoption has mainly originated from outside continental Europe [13]. In a recent article in Intensive Care Medicine, Jung and colleagues retrospectively analysed patients' outcomes after RRT implementation in one hospital (RRT hospital) and compared these to outcomes from three other hospitals (non-RRT hospitals) in the south of France [14]. In essence, the authors replicated a system that was developed 25 years ago and recommended by current resuscitation guidelines [15]. The study showed an impressive decrease in hospital mortality in the hospital with RRT implementation. There are not many interventions in ICU that can be attributed to a similar decrease in mortality and the authors should be congratulated for significant efforts to launch the RRT initiative in their hospital. A cluster randomized trial would, of course, have been ideal to avoid a potential bias due to natural variations in hospital outcomes that might occur over time, but the inclusion of control hospitals decreases this risk [11]. It is also notable that the authors used simple dichotomized ("all or nothing") criteria for calling the MET team. Continuous scoring systems such as the modified EWS (MEWS) may be more accurate but may be more cumbersome for ward staff [16].

It is important to acknowledge that a strategy of RRT implementation will result in higher ICU admission rates and workload [17]. This needs to be taken into account when allocating hospital resources. Previous studies have

\section{Springer}




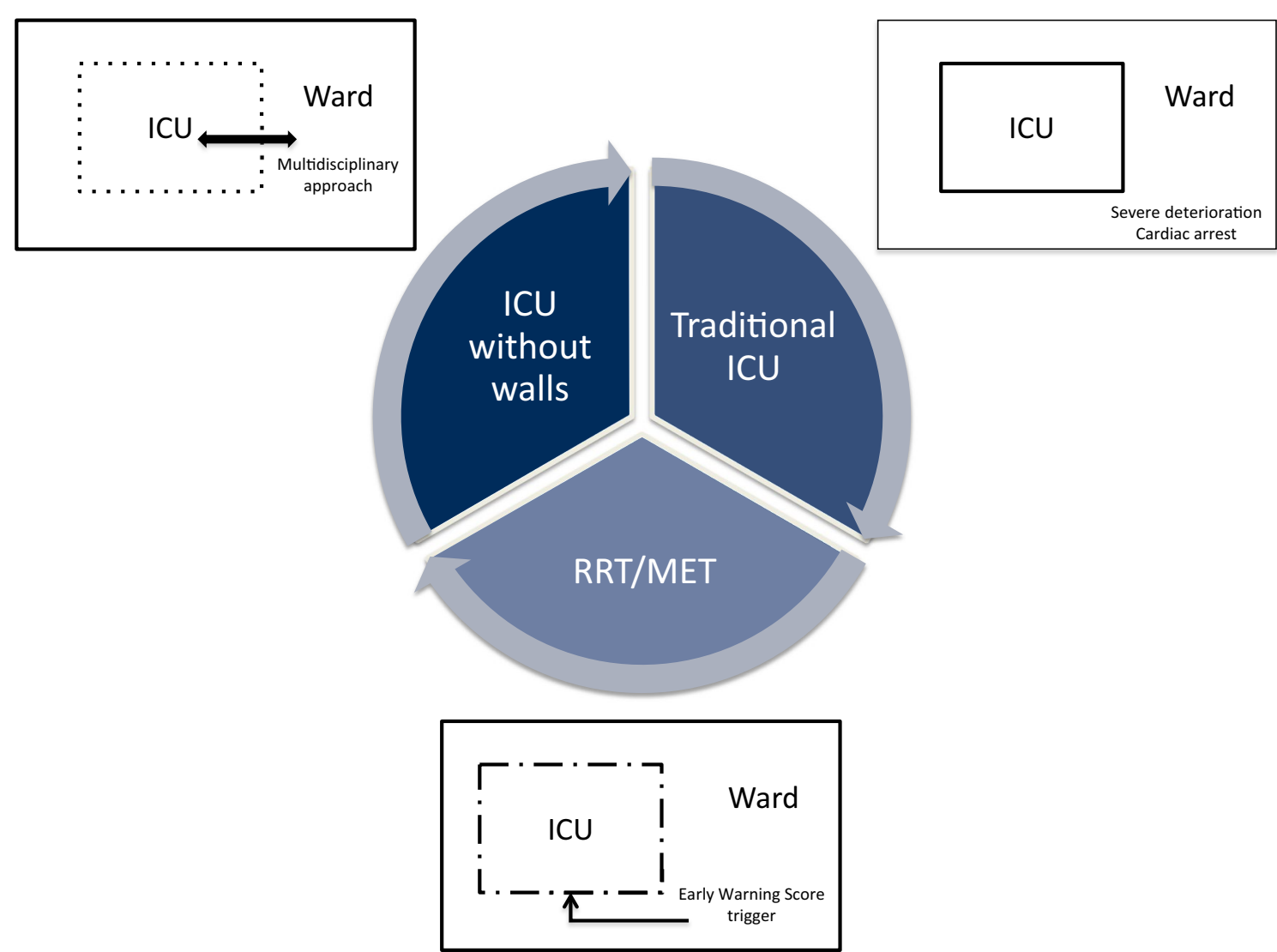

Fig. 1 Current models available for out-of-ICU activity. RRT rapid response team, MET medical emergency team, ICU intensive care unit

shown, as in the study by Jung, a lower severity of illness of ICU admitted patients (manifested by SOFA score) after RRT implementation [17]. This finding might be related to an earlier referral and ICU admission during the course of their illness, but some patients will evidently be admitted "just in case". We need more studies on methods of risk stratification based on an RRT model [18]. Another unavoidable fact is the potential referral and potential source of patients' admission due to futility that are unlikely to benefit from ICU care. The RRT/MET teams often face a big-some might even say too big-role in dealing with treatment limitations on the ward $[19,20]$.

The critical care model advocates for rapid interventions to treat a disease process. This has been facilitated by developments such as new drugs, support equipment, and monitoring technology. It has been largely practised within the four walls of an ICU. However, the number of patients at risk of deteriorating in hospitals is increasing. Thus we need an ICU without walls to focus treatment strategies on prevention, rather than just rapid responses to dramatic problems such as a cardiac arrest (Fig. 1). In the process we can to take into account possibilities and problems encountered in countries with long-standing experience with RRT/MET systems. The Jung and colleagues' results nicely support a body of evidence which suggests that MET/RRT implementation is required, easily adoptable and can make a significant difference for general ward patients at risk of becoming critically ill. Let us hope that this will be well MET in Europe. It is indeed not a moment too soon.

\section{Author details \\ ${ }^{1}$ Division of Critical Care, Department of Anaesthesiology, Intensive Care and Pain Medicine, Helsinki University and Helsinki University Hospital, Helsinki, Finland. ${ }^{2}$ Multidisciplinary Intensive Care Research Organization (MICRO), Wellcome Trust-HRB Clinical Research, Department of Clinical Medi- cine, Trinity Centre for Health Sciences, St James's University Hospital, Dublin, Ireland.}

\section{Compliance with ethical standards}

\section{Conflicts of interest}

Markus Skrifvars is a member of the writing group of the European Resuscitation Council Guidelines on Advanced Life Support.

Received: 9 February 2016 Accepted: 10 February 2016 Published online: 24 February 2016 


\section{References}

1. Chan PS, Krumholz HM, Nichol G, Nallamothu BK, American Heart Association National Registry of Cardiopulmonary Resuscitation Investigators (2008) Delayed time to defibrillation after in-hospital cardiac arrest. N Engl J Med 358(1):9-17

2. Kumar A, Roberts D, Wood KE, Light B, Parrillo JE, Sharma S, Suppes R, Feinstein D, Zanotti S, Taiberg L, Gurka D, Kumar A, Cheang M (2006) Duration of hypotension before initiation of effective antimicrobial therapy is the critical determinant of survival in human septic shock. Crit Care Med 34(6):1589-1596

3. Fuhrmann L, Lippert A, Perner A, Ostergaard D (2008) Incidence, staff awareness and mortality of patients at risk on general wards. Resuscitation 77:325-330

4. Cardoso LT, Grion CM, Matsuo T, Anami EH, Kauss IA, Seko L, Bonametti AM (2011) Impact of delayed admission to intensive care units on mortality of critically ill patients: a cohort study. Crit Care 15(1):R28. doi:10.1186/ cc9975

5. Sandroni C, Nolan J, Cavallaro F, Antonelli M (2007) In-hospital cardiac arrest: incidence, prognosis and possible measures to improve survival. Intensive Care Med 33:237-245

6. Harris S, Singer M, Rowan K, Sanderson C (2015) Delay to admission to critical care and mortality among deteriorating ward patients in UK hospitals: a multicentre, prospective, observational cohort study. Lancet 385(Suppl 1):S40

7. Priestley G, Watson W, Rashidian A et al (2004) Introducing critical care outreach: a ward-randomised trial of phased introduction in a general hospital. Intensive Care Med 30:1398-1404

8. Patient Safety \& Quality Healthcare (2013) IHI launches national campaign to save 100,000 lives in US hospitals. http://www.psqh.com/ janfeb05/100k.html. Accessed 21 June 2013

9. Institute for Healthcare Improvement (2011) Protecting 5 million lives from harm. http://www.ihi.org/offerings/Initiatives/PastStrategicIniti atives/5MillionLivesCampaign/Pages/default.aspx . Accessed 21 June 2013

10. Chan PS, Jain R, Nallmothu BK et al (2010) Rapid response teams: a systematic review and meta-analysis. Arch Intern Med 170:18-26
11. Hillman K, Chen J, Cretikos M et al (2005) Introduction of the medical emergency team (MET) system: a cluster-randomised controlled trial. Lancet 365:2091-2097

12. Smith GB, Prytherch DR, Schmidt PE, Featherstone PI (2008) Review and performance evaluation of aggregate weighted 'track and trigger' systems. Resuscitation 77:170-179

13. Sandroni C, D'Arrigo S, Antonelli M (2015) Rapid response systems: are they really effective? Crit Care 16(19):104

14. Jung B, Daurat A, De Jong A, Chanques G, Mahul M, Monnin M, Molinari N, Jaber S (2016) Rapid response system and hospital mortality in hospitalized patients. Intensive Care Med. doi:10.1007/s00134-016-4254-2

15. Soar J, Nolan JP, Böttiger BW, Perkins GD, Lott C, Carli P, Pellis T, Sandroni C, Skrifvars MB, Smith GB, Sunde K, Deakin CD, Adult advanced life support section Collaborators (2015) European Resuscitation Council guidelines for resuscitation 2015: section 3. Adult advanced life support. Resuscitation 95:100-147

16. Tirkkonen J, Olkkola KT, Huhtala H, Tenhunen J, Hoppu S (2014) Medical emergency team activation: performance of conventional dichotomised criteria versus national early warning score. Acta Anaesthesiol Scand 58(4):411-419

17. Karpman C, Keegan MT, Jensen JB, Bauer PR, Brown DR, Afessa B (2013) The impact of rapid response team on outcome of patients transferred from the ward to the ICU: a single-center study. Crit Care Med 41(10):2284-2291

18. Le Guen MP, Tobin AE, Reid D (2015) Intensive care unit admission in patients following rapid response team activation: call factors, patient characteristics and hospital outcomes. Anaesth Intensive Care 43(2):211-215

19. Jones DA, Bagshaw SM, Barrett J, Bellomo R, Bhatia G, Bucknall TK Casamento AJ, Duke GJ, Gibney N, Hart GK, Hillman KM, Jäderling G, Parmar A, Parr MJ (2012) The role of the medical emergency team in endof-life care: a multicenter, prospective, observational study. Crit Care Med 40(1):98-103

20. Jäderling G, Calzavacca P, Bell M, Martling CR, Jones D, Bellomo R, Konrad D (2011) The deteriorating ward patient: a Swedish-Australian comparison. Intensive Care Med 37(6):1000-1005. doi:10.1007/s00134-011-2156-X 